\title{
Pax Americana ou o império da insegurança?
}

Pax Americana or the empire of insecurity?

ANDREW HURRELL *

Rev. Bras. Polít. Int. 48 (2): 30-54 [2005]

\section{Introdução}

O objetivo deste artigo é determinar o papel e a posição dos Estados Unidos em um contexto abrangente e histórico e tentar escapar da imediatez da discussão corrente sobre as escolhas estratégicas que Washington fez, está em vistas de fazer, ou que poderá fazer no futuro. $\mathrm{O}$ artigo está dividido em três partes. Na primeira seção, apresenta-se o questionamento de algumas premissas que são constantemente feitas sobre a noção de império, particularmente sobre a inevitabilidade de seu fim sobre a redundância e o anacronismo do império como forma de ordem política, e a conseqüente implicação de que o foco natural das relações internacionais devem ser as relações entre Estados ou Estados-nação. A profunda extensão do poder dos Estados Unidos e a aparente obviedade da opinião de que estamos vivendo em um mundo unipolar trouxeram de volta a linguagem de império e têm levado muitos a ver os Estados Unidos como um poder imperial. A segunda seção considera como devemos entender esse poder. A argumentação de que noções de império informal oferecem algumas vantagens analíticas, mas negligenciam a importância do papel do poder militar e da coerção na evolução da política externa americana, e a importância de regras, normas e instituições - o que pode ser chamado do lado formal do dito império informal. Também é discutido que é analiticamente mais útil compreender os Estados Unidos como um hegemon a vê-lo como um poder imperial porque, ao fazê-lo, o analista é forçado a concentrar-se diretamente em questôes cruciais tais como negociação, legitimidade e a necessidade do hegemon conseguir adeptos e seguidores. Muitos acreditam que hegemonia é uma forma de controle mais superficial e menos impactante que império. Embora isso seja verdadeiro de certa forma, sugere-se que a hegemonia dos Estados Unidos é marcada por várias forças históricas e estruturais

\footnotetext{
* Professor de Relaçôes Internacionais, Nuffield College, Universidade de Oxford (andrew.hurrell@ nuffield.oxford.ac.uk). Este artigo foi traduzido do inglês por Rogério Farias e Priscilla Tanaami. O autor agradece a excelente assistência de pesquisa de Matias Spektor e Miriam Prys.
} 
que têm empurrado esse país em direção a um envolvimento mais profundo e intrusivo no resto do mundo e que continuam a fazê-lo, dificultando o exercício do poder norte-americano.

$\mathrm{Na}$ terceira seção se examina de forma mais geral as cinco razões mais citadas para a rejeição de concepções imperiais e verticalizadas do ordenamento internacional. Em vez de comparar a extensão e o caráter do poder dos Estados Unidos com o de outros Estados hegemônicos na história, se questiona como esses cinco fatores podem ter mudado de forma a viabilizar um ordenamento hegemônico e potencialmente sustentável. Claramente, as fontes de poder dos Estados Unidos são enormes. No entanto, quando confrontadas com o modo em que a sociedade internacional e a política global vêm mudando, o que mais chama a atenção são os limites, a instabilidade e as incertezas desse poder. Embora essas limitações apliquem-se mais diretamente ao exercício do poder coercitivo, suas implicações são mais amplas e questionam a imagem simplista dos Estados Unidos como um poder hegemônico todo-poderoso e sem rivais.

\section{Impérios e ordem}

A noção de império foi, durante muito tempo, central para as concepções de ordem mundial. Isso era claramente verdade nas relações internacionais antes da emergência do sistema europeu clássico de Estados. Mas o imperialismo também era central para a operação política do sistema clássico de Estados, para seu desenvolvimento econômico, para o caráter da ordem internacional legal e normativa e, como muitos trabalhos recentes têm mostrado, para sua teoria política. A lógica de poder em um sistema de Estados clássico deu origem a dois padróes persistentes: primeiro, de equilíbrio de poder e, segundo, de desigualdade e hierarquia. O campo do estudo acadêmico das Relaçôes Internacionais deu enorme atenção ao primeiro padrão, mas negligenciou o segundo e subestimou o papel crucial da interação entre poder equilibrado e poder desigual na gênese da ordem internacional. Da mesma forma, a disciplina de Direito Internacional enfatiza tanto a idéia do direito internacional como um sistema horizontal de coordenação (desfazendo analogias equivocadas com o âmbito doméstico, onde o foco é na implementação, por vezes forçada, de decisōes), que acaba desviando sua atenção do importante tema dos diferenciais de poder e do papel da desigualdade entre Estados.

O sistema de Estados clássico não somente foi marcado por desigualdades, como foi estruturado em torno delas. A combinação do rápido desenvolvimento industrial, a emergência de estruturas estatais administrativas organizacionais mais eficientes, a consolidação dos Estados nacionais e mudanças na tecnologia e na organização militar levaram à ascensão de um pequeno número de grandes potências que dominaram o cenário da política internacional. No núcleo do sistema, formas institucionalizadas de hierarquia foram centrais em dois aspectos: por um lado, na compreensão pluralista de como sustentar o ordenamento internacional; por outro, 
na geração das normas políticas que institucionalizaram esses entendimentos. Embora a lógica do equilíbrio de poder pudesse operar automaticamente, suas ameaças e atritos poderiam ser minimizados pelo reconhecimento do papel gerencial das grandes potências. Elas poderiam promover a ordem gerenciando as relações entre si (por meio da diplomacia, conferências, missōes, e intervenções conjuntas), assim como explorando seu diferencial de poder em relação a Estados subordinados, esferas de influência e sistemas de alianças. Apesar do movimento normativo em direção a maiores graus de igualdade, esse padrão permaneceu central durante a maior parte do século XX.

Se a desigualdade marcou o cerne do sistema de Estados, as relaçóes entre o núcleo europeu e a periferia foram ainda mais desiguais. A Revolução Industrial e as inovaçóes tecnológicas em armamentos forneceram a base para uma dominação sem paralelos dos poderes europeus sobre o resto do mundo. $\mathrm{O}$ sistema clássico de Estados era uma ordem imperial e colonial. Essa face imperialista precisa ser entendida como uma das principais instituições da sociedade internacional. Dessa forma, a ordem européia colonial foi construída em torno de territórios formalmente subordinados que não tinham papel algum nas relações internacionais, pois tratavase de um sistema econômico marcado pela imposição da abertura das economias periféricas, pela abertura demográfica das mesmas, por premissas culturais que enfatizavam a superioridade da cultura ocidental e branca, e pela crença em que o progresso era uma conseqüência da reprodução de modelos europeus - uma premissa verdadeira tanto para Marx como para Mill.

Mas, talvez, mais interessante que a centralidade histórica da noção de império é a forma como uma gama de representantes de diferentes pensamentos políticos via a mesma, não como um resquício de um passado feudal, mas sim como um elemento central das relações internacionais do futuro; e, particularmente, como uma resposta às mudanças impostas pelo desenvolvimento capitalista e pelas forças do que veio a se chamar de globalização. Três momentos merecem atenção.

Escrevendo no auge da autoconfiança imperial vitoriana, John Seeley ressaltava a transformação na escala de poder, as "vastas forças unificadoras" do comércio, investimento e migração, assim como a extensão em que mudanças tecnológicas e de comunicação estavam facilitando novas formas de organização política. "Eu tenho sugerido que no mundo moderno a distância tem perdido muito seus efeitos, e que existem sinais de um tempo no qual os Estados vão ser mais vastos do que eles têm sido até o presente" (Seeley [1881] 1971: 234). Em consonância com muitas das reflexões do pensamento do século XIX (por exemplo, Cobden [1867] 1903: 5-119 e 122-258; para a visão admirável de Cobden do poder dos Estados Unidos, ver Cowley, 1952), ele via a lógica dominante da integração econômica e interdependência apontando para consolidação e fusão de estruturas políticas. E, como vários de seus contemporâneos, ele via os Estados Unidos como modelo: "o mais notável 
exemplo de expansão confiante e bem sucedida", um modelo de instituições livres combinadas com uma expansão sem limite em seu maior grau...é precisamente o tipo de união que as condiçōes de nossa época mais naturalmente necessitam. (Seeley [1881] 1971: 235/236).

Escrevendo em 1926, Alfred Zimmern, o principal pensador liberal e defensor da Liga das Nações, também via o império como um elemento necessário e benéfico à futura ordem mundial. Assim como Seeley, ele acreditava que transformações econômicas mudavam os imperativos tanto do poder nacional como os de governança internacional. "Historiadores futuros, eu acredito, vão olhar para o século XIX como um século que uniu o mundo economicamente, por intermédio do desenvolvimento de um sistema mundial de comércio, indústria, e comunicações; e eles vão apontar para o século XX como o que regularizou e controlou esses contatos econômicos, pelo desenvolvimento de uma cooperação intergovernamental e pelo estabelecimento de uma base firme para o direito internacional como um sistema de regras vinculantes entre os Estados". (Zimmern, [1934] 1979: 60/61). Nessa busca por governança, contudo, o império continuaria a ter um papel central. De um lado, a Commonwealth britânica representava, para Zimmern, um modelo para a Liga das Nações - um modelo de associação livre e pacífica de Estados e comunidades nacionais. Do outro, a Liga das Nações era central para a sobrevivência e sustentabilidade da Commonwealth, daí a noção de Zimmern de "uma liga dentro de outra mais ampla, uma sociedade dentro de uma sociedade maior". (Zimmern, [1934] 1979: 61). Esse pequeno lapso entre liberais internacionalistas e liberais imperialistas não era de forma alguma restrito a Zimmern. Assim, Wilson defendia a Doutrina Monroe em Paris, não como um arranjo regional hegemônico que refletia os interesses egoístas dos Estados Unidos, mas como um modelo para a Liga. Essa idéia tinha sido discutida em novembro de 1914, e era expressa em vários documentos e no discurso de Wilson no Senado (22 de janeiro de 1917), como tentativa de tornar a Liga aceitável para a opinião pública norte-americana. Mas essa idéia também refletia, de acordo com a proposta de House, que Wilson adotou com entusiasmo, uma crença genuína de que um Pan-Americanismo, inspirado na Doutrina Monroe, poderia fornecer um modelo de organização internacional para o pós-guerra (Gilderhus, 1986: 135-139 e Gilderhus, 1980: especialmente 415-417).

Ao final da Segunda Guerra Mundial, a maré contrária à noção de império parecia avançar com mais força. De fato, a guerra em si foi crucial no processo de descolonização: a devastadora fraqueza do núcleo europeu, a ascensão das superpotências (termo cunhado em 1944), a perda do controle direto sobre territórios coloniais (especialmente na Ásia), e a intensificação do nacionalismo anticolonial alimentado em oposição à tentativa européia de mobilizar os impérios para o esforço de guerra. Os conflitos catastróficos da primeira metade do século XX, pareciam reforçar a idéia difusa, mas generalizada, de que a 
época dos Estados-nação chegava no fim e que as forças políticas internacionais e o desenvolvimento do capitalismo global estavam levando a novas formas de ordenamento político (por exemplo, Carr, 1945). Mas nesses debates a noção de hierarquia permanecia central. Por vezes, a ligação entre hierarquia e ordem era focalizada em instituiçóes, como no caso das Nações Unidas, com o entusiasmo (consistente) de Churchill e (inicial) de Roosevelt por uma ordem construída em torno dos "quatro policiais", cada um mantendo a ordem em suas respectivas esferas de influência. Às vezes, a ênfase recaía mais diretamente na noção de império. Alexandre Kojève, o grande especialista em Hegel e oficial do governo francês, oferece um exemplo particularmente interessante de como a percepção dessas mudanças apontava tanto para a centralidade continuada da noção de império como para a mudança de seu caráter.

Em seu trabalho Outline of a Doctrine of French Policy, escrito em agosto de 1945, ele escreveu: "No presente, são esses Estados-nação que, inexoravelmente, estão de forma gradual dando lugar a formações políticas que transcendem fronteiras nacionais e que podem ser designadas pelo termo 'Impérios'. Estadosnação, ainda poderosos no século XIX, estão cessando de ser realidades políticas. (...) O Estado moderno, a realidade política corrente, requer uma fundação maior do que aquela representada por Naçóes no sentido estrito. Para ser politicamente viável, o Estado moderno deve ser baseado em uma 'vasta união "imperial” de Naçôes afiliadas'. O Estado moderno só é realmente um Estado se for um Império" (Kojève, 1945). Na visão de Kojève, a Alemanha nazista tinha reconhecido essas mudanças, como pode ser visto nos extensos debates sobre Grossraumtheorien e na geopolítica de Haushofer (que influenciariam Spkyman e, depois, Kennan) ${ }^{1}$. Mas, para Kojève, a Alemanha tinha procurado uma solução nacional que estava fadada ao fracasso quando confrontada pelo "socialismo imperial" da URSS, de um lado, e pelo 'capitalismo imperial dos Anglo-Saxões', do outro. "Pode-se dizer, portanto, que a Alemanha perdeu essa guerra porque queria ganhá-la como um Estado-Nação". Assim como Zimmern, ele via a Commonwealth como um modelo, mas argumentava que esse era um modelo ainda muito nacional. E, de novo de acordo com Zimmern, o futuro estava do lado dos Estados Unidos, com seus arranjos desterritorializados e estruturados de maneira muito mais difusa. "É o império Anglo-Saxão, o que significa dizer o bloco político-econômico Anglo-americano, que é hoje a realidade política efetiva" (Kojève, 1945: 3). As soluçóes do próprio Kojève apontavam, de forma presciente, para o regionalismo (a outra unidade óbvia da ordem mundial além do Estadonação) e, de forma profundamente implausível, a noção de "Império Latino".

Politicamente, é claro, o período pós-Segunda Guerra Mundial presenciou o desafio dos territórios europeus ultramarinos de se fortalecer, levando à conclusão da terceira onda de descolonização (contra os impérios europeus) e,

\footnotetext{
1 Sobre o engajamento de Kojève com Schmitt e Aron ver Müller, 2003, especialmente Visions of Global Order: Schmitt, Aron, and the Civil Servant of the World-Spirit, 87-103.
} 
finalmente, à quarta onda (com a quebra do império soviético e do sistema hegemônico). Analiticamente, a disciplina de Relaçôes Internacionais insistia ainda mais em descrever o seu campo de estudo como "A Política entre as Nações" ou como a política de um sistema inter-estatal anárquico, apesar do importante papel da hierarquia nos dois lados da Guerra Fria. George Liska foi inusual ao salientar o caráter dual ou variado do sistema. "A política internacional contemporânea", ele escreveu em 1967, "é um agregado de dois ingredientes: a política dos Estados-nação renovados ou fortalecidos e a política de império e das relações interimperiais" (Liska, 1967: 3).

A emergência dos Estados Unidos como núcleo de um mundo unipolar reforçou a atenção dada às implicações da recentralização do poder global não simplesmente em relação às escolhas estratégicas dos Estados Unidos, mas, mais amplamente, em termos da possibilidade de gerar ordem mediante hierarquia, hegemonia ou até mesmo império. Falar dos Estados Unidos como a nação indispensável tornou-se mais persistente e, para muitos, mais persuasivo; e a caracterização de Krauthammer de um "momento unipolar" abriu espaço para a crença de que o mundo havia entrado em uma era unipolar (ver Brooks e Wohlforth, 2002). Ambos, império e hegemonia, requerem poder, propósito e apoio político de terceiros. Como os muitos catalogadores e contadores de recursos objetivos de poder notaram, os recursos dos Estados Unidos não têm rival: a verba militar dos Estados Unidos é maior que a dos 14 países seguintes juntos e a economia dos Estados Unidos é maior do que as próximas três combinadas. Mas foram, é claro, os eventos que se seguiram ao 11 de Setembro que pareceram oferecer aos Estados Unidos um propósito muito mais claro (e talvez um projeto), assim como níveis muito maiores de apoio político doméstico, a uma política externa ativa e engajada. A emergência de uma política externa mais unilateral e nacionalista por parte dos Estados Unidos reforçou ainda mais o retorno à linguagem de império. Como resultado, um número cada vez maior de comentadores passou a falar do papel dos Estados Unidos no mundo em termos imperialistas (para um exame mais detalhado, ver Cox 2003; Bacevich, 2002: 142-43; Ferguson, 2002; Ikenberry, 2002; and Snyder, 2003) e, de modo também crescente (tanto à direita como à esquerda), outros passaram a defender as virtudes de um Império Americano - como a melhor política para salvaguardar os interesses nacionais norte-americanos; como a única fonte possível de segurança global e outros bens públicos internacionais; como o único Estado com a capacidade de comprometer-se com as tarefas de intervenção e state-building que o caráter evolutivo da própria segurança torna vitais; e como o agente político essencial para a expansão do liberalismo global.

\section{Definições e distinções}

A caracterização dos Estados Unidos como um poder imperial sempre foi difícil e contestada. Assim, o clássico retrato de Ernest May da ausência de uma 
inclinação imperial pode ser contestado com a igualmente clássica exposição de Williams de Empire as a Way of Life (May, 1968 and Williams, 1980). É claramente o caso que os Estados Unidos têm, há muito tempo, mantido uma poderosa imagem de si como um poder anticolonial, com sua rejeição à política de poder européia; sua sustentada e recorrente retórica de liberdade e autodeterminação; seu papel decisivo no estabelecimento da autodeterminação como uma norma política internacional; e sua pressão direta sobre os Estados europeus para que abdicassem de suas possessões imperiais, desde os holandeses na Indonésia até os franceses e britânicos em Suez.

Contra isso, no entanto, os Estados Unidos têm que ser vistos como um produto da expansão européia, que envolveu assentamento de colônias e a subjugação de povos indígenas e independentes. $\mathrm{O}$ país era forte territorialmente e bem sucedido em sua dimensão expansionista no decorrer do século XIX via colonização, compra de terras e guerra (usando a força mais de cem vezes entre 1807 e 1904). Ademais, quando o país abandonou a expansão territorial e a conquista, não o fez notadamente por fatores liberais. Dessa forma, é inegável que preocupações liberais tiveram um papel: em termos das ameaças à liberdade doméstica associadas com a expansão imperial no exterior, e na dificuldade de reconciliar a realidade do império e o domínio ultramarino com os valores norte-americanos. Mas raça e escravidão também foram fatores dominantes para explicar o fim da expansão rumo ao sul e para levar os Estados Unidos a novas formas de controle territorial - como a doutrina de territórios nãoincorporados ou arranjos de protetorados, como a Emenda Platt, que serviu de modelo para o Haiti, Nicarágua, Republica Dominicana e que, por sua vez, havia sido aplicada com base no modelo de domínio britânico no Egito. E, como Morgenthau e outros já observaram, nunca houve um imperativo geopolítico pró-expansionista forte. "Raramente, se não nunca, poderia uma grande potência atuar com uma política de conquista com menos convicção, determinação e senso de propósito". Para os Estados Unidos, conquistas além dos limites do continente norte-Americano eram, desde o início, um inevitável embaraço, mais que a realização de um objetivo nacional' ${ }^{2}$. Onde esse imperativo realmente existia, como era o caso dos chamados Strategic Trust Territories, então a conquista não era renunciada. Igualmente, quando a geopolítica ditava rearranjos territoriais e a permuta de povos e soberanias (como ocorreu tanto

${ }^{2}$ MORGENTHAU, 1960: 99-101. A discussão de Morgenthau é fascinante conforme ele enreda (de forma um tanto não convincente) no papel do propósito moral. "Os moralismos exagerados com os quais a expansão americana tem sido tradicionalmente justificada, então, contêm elementos de sinceridade subjetiva, mas também de verdade objetiva. A idéia de uma missão americana para os povos menos afortunados do mundo é certamente uma ideologia política, a racionalização e justificação de políticas foram empreendidas por outras razões, principalmente egoístas. Mas a idéia expressa também um sério comprometimento com um propósito que é meramente o objetivo americano projetado além de seus limites territoriais e circunscrito somente pelo alcance da influência americana". Para uma explicação da expansão dos Estados Unidos e seus limites, ver ZAKARIA, 1998. Sobre o papel da competição, em que Zakaria presta pouca atenção, ver SCHOULTZ, 1999. 
em Paris em 1918, como em Yalta em 1945), os Estados Unidos, então, estavam dispostos a seguir seus interesses em vez de seus professados valores, abrindo espaço à recorrente acusação de ser um conspirador maquiavélico por trás de uma fachada Wilsoniana.

Ainda assim, os Estados Unidos distanciaram-se da conquista formal e da anexação territorial, buscando expansão econômica externa e a abertura de mercados. É isso que nos força a lidar com os aspectos não-territoriais do poder norte-americano e com a distinção entre império formal e informal, entre controle político direto (hasteando bandeiras e pintando mapas) e controle econômico informal (abrindo as portas da economia; para a exposição clássica ver Gallagher e Robinson, 1953). Essa diferenciação permanece crucial para o entendimento do poder dos Estados Unidos, mas sofre de duas sérias limitações. A primeira é que negligência a disposição continuada, por parte dos Estados Unidos, de usar a força e a coerção na busca de seus interesses. É essa disposição uma das características mais importantes que distingue hegemonia de primazia livremente reconhecida. Em áreas onde sua hegemonia estava estabelecida há muito tempo, como na América Latina, intervencionismo e uso da força mantiveram-se presentes mesmo quando o caráter do sistema internacional passou por dramáticas mudanças. Por isso, por exemplo, intervencionismo não pode ser entendido como uma função dos constrangimentos da Guerra Fria. Além disso, conforme o poder relativo dos Estados Unidos cresceu e as restrições da Guerra Fria diminuíram, aumentou sua disposição de usar a força. Assim, Bacevitch (2002: 142-43) indica a existência de um "nível de ativismo militar sem precedentes" durante os anos 90, e 48 intervenções militares levadas a cabo durante os anos Clinton.

O segundo problema é a tendência a ignorar os aspectos "formais" do império informal. Essa foi uma falha da formulação original do conceito e, ainda mais, em suas aplicaçōes ao caso norte-americano. Historicamente, a prática do império informal envolveu um complexo conjunto de normas e arranjos institucionais (a respeito de, entre outros, extraterritorialidade, protetorados, territórios não-incorporados, esferas de influência, assim como normas relativas à soberania, autodeterminação, ou sua ausência, e ao uso da força). As normas fundamentais da sociedade internacional estavam marcadas permanentemente pelo seu caráter dual tanto de sistema interestatal como de sistema inter-imperial. Hoje, o lado formal do império informal torna-se ainda mais crucial para a projeção de poder norte-americano, já que as regras e instituições em torno das quais a globalização é estruturada, tornam-se cada vez mais ambiciosas, intrusivas e abrangentes. Uma grande parte do poder norte-americano é exercida pela "metamorfósica" estrutura normativa e legal da sociedade internacional - por intermédio da influência norte-americana sobre normas centrais (por exemplo, aquelas relativas ao uso da força ou à modificação do caráter da soberania); pela influência dos Estados Unidos em 
regimes e instituições dos quais escolhe não participar; por sua capacidade de influenciar escolhas entre modos de governança de mercado ou políticos; e por seu cultivo de modos alternativos de governança (por exemplo, a expansão de redes regulatórias ou a externalização de seu direito doméstico). Assim, a visão dos Estados Unidos como sendo ou 'a favor' ou 'contra' o direito internacional e instituições é altamente enganosa e corre o risco de desviar nossa atenção das formas pelas quais o poder dos Estados Unidos é realmente exercido.

Isso leva ao segundo tópico, a saber, a distinção entre o controle coercitivo direto, por um lado, e o controle exercido por regras e instituições e mediado por negociação, por outro. Para muitas pessoas, a inevitabilidade do termo "império" parece decorrer naturalmente do imenso manancial de recursos de poder à disposição de Washington e, especialmente, da extraordinária capacidade militar lhe dá uma aparente dominação avassaladora sobre seus adversários. Império (em vez de hegemonia ou primazia), parece particularmente apropriado para o uso direto de coerção em relação aos Estados mais fracos e subordinados, não mediada por negociações políticas, regras acordadas ou instituições compartilhadas. No entanto, a visão do poder em termos puramente coercitivos e materiais, baseia-se em um entendimento do poder bastante limitado e pouco útil. $\mathrm{O}$ poder nas relações internacionais deve ser visto como uma relação social, posto lado a lado com outros conceitos sociais essenciais como prestígio, autoridade e legitimidade. Grande parte da luta por poder político é a busca de controle legítimo, evitando o apelo, custoso e perigoso, à força bruta e à coerção.

Teóricos do imperialismo nos ensinaram, há muito tempo, que impérios formais dependiam de uma variedade de controles indiretos, e que o fim do império chegou quando os imperialistas ficaram sem colaboradores. Se isso era verdade para impérios formais, o é ainda mais para impérios informais e sistemas hegemônicos. É por essa razão que o conceito de hegemonia é tão importante. Afinal, uma hegemonia estável se apóia em um delicado equilíbrio entre a coerção e o consenso; entre o exercício do poder direto e indireto do Estado hegemônico, por um lado, e, por outro, a provisão de algum grau de autonomia de ação e respeito para os Estados mais fracos. Apesar de ênfases e implicações poderem variar, essa descrição geral é adequada tanto se adotarmos visões realistas, liberais ou neogramscianas de hegemonia ${ }^{3}$. Diferentemente da subordinação direta, a hegemonia precisa ser estruturada em um processo de negociação constante e comumente instável, entre o forte e o fraco. Negociação

\footnotetext{
${ }^{3}$ Abordagens liberais e neogramscianas são muito bem abrangidas na literatura. No lado conservador, o teórico mais importante (e seriamente negligenciado) é Triepel, 1938. Triepel insistiu na distinção entre liderança, hegemonia e dominação; ele argumentava que hegemonia "requer adeptos por definição" e acarreta a integração de Estados subordinados dentro de uma ordem que parece benéfica a eles. Ele fala explicitamente sobre a necessidade de autocontenção estratégica (Selbstbändigung des Machttriebs, p.131), e de que o hegemon exerça poder de um modo indireto que incentivará os Estados subordinados em direção ao seu comportamento e seus valores. Agradeço Miriam Prys pela assistência na pesquisa desse ponto.
} 
e o cultivo de legitimidade têm um papel crucial, especialmente dada a natureza mutável do conteúdo das políticas em um mundo globalizado.

Se a modalidade de controle é melhor encapsulada pelo termo "hegemonia", o terceiro tópico relaciona-se à profundidade do envolvimento norte-americano. A intuição óbvia é que hegemonia e império informal implicam um envolvimento menos profundo e esforços menos intrusivos tanto para moldar regimes subordinados às preferências do hegemon, como para proteger-se de rivais estratégicos. Na visão de Gallagher e Robinson, o império informal é mais flexível, mais barato e menos arriscado, e é essa a razão de a Grã-Bretanha tê-lo preferido sempre que possível. A mesma lógica e os mesmos benefícios devem aplicar-se aos Estados Unidos, também sendo um império informal mais coerente com seus valores.

Contra essa visão, contudo, há claros exemplos nos quais os Estados Unidos envolvem-se profundamente em iniciativas para remodelar unidades políticas subordinadas. Pode-se apontar, por exemplo, as tentativas de state-building colonial durante a fase mais aguda do fervor intervencionista entre 1898 e a Política da Boa Vizinhança de 1933, especialmente em Cuba, no Haiti e nas Filipinas. O "Fardo do Homem Branco" de Kipling era, afinal, endereçado e dedicado não ao Império Britânico, mas à ocupação norte-americana nas Filipinas (Kramer, 2002: 1348). Fora isso, as pressões da Guerra Fria impulsionavam os Estados Unidos em direção a iniciativas ainda mais expansivas e ambiciosas de promoção da democracia, desenvolvimento econômico e reformas sociais pacíficas, mais notadamente no caso da Aliança para o Progresso nos anos 60. A Aliança foi o maior esforço norte-americano nesse sentido, entre as ocupações do Japão e da Alemanha na década de 1940, e o renascimento de tentativas de nation-building dos anos 90 . E foi quase um fracasso total ${ }^{4}$.

\footnotetext{
${ }^{4}$ A Aliança tem sido curiosamente negligenciada nos debates recentes sobre a viabilidade de nationbuilding (e por historiadores, mais genericamente). Apesar de ter havido alguns sucessos, no fim dos anos 60 , os limites e fracassos estavam claros e as razōes para estes permanecem relevantes. Primeiramente, as metas de longo prazo da democracia e desenvolvimento foram consistentemente subestimadas pelas necessidades de curto prazo de segurança e, especialmente, contra-insurgência. Em segundo lugar, a necessidade de reduzir os fardos levou os Estados Unidos a abraçar uma gama de títeres não confiáveis e ignóbeis. Esses foram os coronéis e generais que assumiram o poder no crepúsculo da democracia nos anos 60. Conforme eles se tornaram firmemente estabelecidos no poder, Washington passou a considerar o controle indireto cada vez mais difícil (proxy tails wagging hegemonic dogs), e os Estados Unidos se corromperam por seu apoio a inimigos da democracia e às atividades reprováveis de seus colaboradores torturadores. Realmente esse período mina a visão dos Estados Unidos como um apoiador consistente da democracia e dos direitos humanos e é essa aparente cegueira a essa realidade que engendra o cinismo estrangeiro atualmente. E, em terceiro lugar, a Aliança falhou devido às dificuldades da nation-building até mesmo numa região onde o poder dos Estados Unidos era imenso, onde os Estados Unidos tinham tanto patrimônios de conhecimento e cultura, e onde ele havia feito um compromisso público. Foi esse fracasso que contribuiu para muitas das mais importantes análises da época, especialmente PAKENHAM, 1973 e HUNTINGTON, 1968 - a bíblia para aqueles que buscavam justificativa para o apoio dos Estados Unidos a regimes autoritários, até que a terceira onda de democratização e o fim da Guerra Fria empurraram muitos da direita de uma forma extrema de impossibilidade democrática para uma crença igualmente exagerada na universalidade de possibilidades de democracia e da promoção desta.
} 
Mas a questão mais importante é se não existem pressões mais profundas e permanentes em prol de maior envolvimento norte-americano. Um conjunto de pressóes origina-se da recorrente ambição política e moral dos Estados Unidos de melhorar o mundo e exportar os seus valores. "Eu estou buscando o mínimo de interferência necessária para torná-los bons" disse Theodore Roosevelt em 1908, em relação a Cuba e à América Central. Mas, seja em 1908 ou em 2004, é altamente improvável que fazer os povos melhores, ou até moderadamente menos piores, seja um objetivo a ser realizado com doses mínimas de interferência. Outro conjunto de pressões pode ser derivado do caráter mutável dos interesses econômicos dos Estados Unidos. Ao contrário do envolvimento britânico no comércio e no investimento de portfólio, a expansão dos interesses econômicos norte-americanos durante o século XX, envolveu investimentos na produção e exploração de matérias primas, comumente à sombra de barreiras tarifárias de bem-sucedidos arranjos de substituição de importação que dominaram o crescimento econômico de boa parte do mundo durante grande parte do século. Manter-se nesse âmbito significava, inevitavelmente, que os Estados Unidos estariam envolvidos na política doméstica de diversos países ao redor do planeta com mais intensidade que a Grã Bretanha. Além disso, o caráter mutável da regulação econômica global, relacionado, de um modo ou de outro, aos interesses dos Estados Unidos, tem, cada vez mais, envolvido regras amplamente intrusivas, cujo valor depende de sua internalização e implementação nessas sociedades.

Esse ponto crucial pode ser mais generalizado. A promoção dos interesses dos Estados Unidos em uma era globalizada tem, cada vez mais, envolvido a intrusão profunda na forma como diferentes sociedades devem ser organizadas domesticamente, sendo essa uma mudança estrutural. Se os Estados devem desenvolver políticas efetivas para o desenvolvimento econômico, proteção ambiental, direitos humanos, resolução de crises de refugiados, narcotráfico e terrorismo, então eles precisam engajar-se com uma ampla gama de atores internacionais e transnacionais e interagir não só com governos centrais, mas com um conjunto muito mais diversificado de atores políticos domésticos, econômicos e sociais. Se os Estados Unidos desejam resolver problemas em um mundo globalizado, não podem simplesmente persuadir ou intimidar governos a assinar tratados; terminam, inevitavelmente, envolvidos na condução dos negócios domésticos e na organização interna dessas sociedades. Essa tendência tem sido reforçada pela transformação da agenda de segurança e, como eu argumentarei em seguida, esse é um dos fatores mais importantes que tem reformulado o debate sobre legitimidade e, uma vez mais, complicado o exercício do poder hegemônico.

Finalmente, sempre tem sido extremamente difícil para impérios e potências hegemônicas definir e limitar seus interesses. As Relaçóes Internacionais como disciplina têm costumado a pensar o sistema político 
internacional em termos neo-realistas: um mundo no qual sistemas "constrangem", empurrando e forçando os Estados a agirem de determinadas formas. A desigualdade de poder e a falta de competidores políticos tradicionais em termos de poder, levam analistas naturalmente a privilegiar fatores domésticos norte-americanos. Daí o argumento comum que, em um período de unipolaridade, a política dos Estados Unidos deve ser explicada em termos de grupos de interesses (empresariais ou petrolíferos), ou ideologia (a ascensão dos neoconservadores). Daí, também, o foco nas formas pelas quais Estados hegemônicos ou imperiais são levados a realizar escolhas políticas e, em particular, estão tentados à expansão excessiva pelas pressões de grupos de interesse domésticos e pelos "mitos de império" domésticos, do tipo analisado percucientemente por Jack Snyder (Snyder, 1991).

Esse modo de pensar tem méritos, mas também limites. Impérios sempre enfrentam vários dilemas estratégicos genuínos que estão enraizados na natureza do sistema, não em política doméstica; e o analista deve colocar muito mais ênfase na forma pela qual os sistemas "constrangem", não só pela forma que eles empurram e pressionam, mas também pela forma como eles aprisionam. Manter um império de forma bem sucedida é uma tarefa extraordinariamente difícil. No caso da Grã Bretanha, o que a fez se mover do império informal para o formal foi, diversas vezes, a rivalidade estratégica em termos consistentes com o neo-realismo; mas também foi freqüentemente o resultado de mudanças socioeconômicas na periferia, de crises locais que pareciam ameaçar a estabilidade do controle e o prestígio do poder imperial, e de uma grande variedade de pontos conectando o exterior imperial com o interior local (Darwin, 1997). Conforme o sistema distancia-se da era dos impérios formais, as opções disponíveis para a as potências têm sido repetidamente constrangidas pelas ações dos fracos e pelas instabilidades da periferia. Ao contrário do que afirmam os neo-realistas (especialmente os neo-realistas defensivos), não pode haver um equilíbrio estável de poder nem uma definição de interesse inconteste. Como nota Hoffmann, "quase tudo pode ser descrito como interesse vital, já que até mesmo desordem na periferia pode desestabilizar a eminência de uma superpotência" (Hoffmann, 2004: 35). Isso deveria também prevenir contra tentativas de entender as políticas dos Estados Unidos em termos de suas próprias escolhas estratégicas. Assim como na questão de legitimidade, o foco do estudo precisa estar nos objetos do poder norte-americano, assim como nos objetivos da política norte-americana. Equilíbrios e barganhas locais podem ser tão vitais quanto grandes negociações estratégicas.

O debate sobre a coerência da expansão norte-americana e o balanço entre os diferentes componentes do interesse do país é muito grande para ser resumido aqui. Não é difícil refutar a visão dos Estados Unidos como um país puramente reativo aos eventos do mundo exterior. Em um sentido importante, os Estados Unidos têm sempre sido um Estado revisionista, tanto em sua 
posição de cruzado como de farol ${ }^{5}$. Mas a noção de "império por convite" também constitui uma parte importante do retrato histórico (principalmente em relação à Europa), assim como a aquisição de poder predominante, se não por acidente, então certamente como resultado da busca de outros objetivos mais importantes, principalmente ganhar grandes guerras. Mas o que se procurou salientar aqui é que os fatores de pressão por trás da política norteamericana devem ser entendidos em um conjunto mais complexo de questôes relativas à manutenção do poder, mesmo na falta de um rival estratégico direto.

\section{A sustentabilidade da hegemonia}

Nesta seção serão examinados cinco fatores comumente citados como causas para o fim dos impérios no século XX: a utilidade declinante da força militar; resistência ao domínio estrangeiro; mudanças nas próprias metrópoles; mudanças no ambiente internacional em sua interface legal e moral; e a existência de oponentes e rivais. Esses fatores também estão por trás de aspectos mais amplos, como a difusão e descentralização do poder que, para autores como Hedley Bull e Adam Watson, caracterizaram o período de 1900 até o final da década de 1970. Nesse sentido, a descolonização e o fim do império foram apenas um dos elementos da revolta contra a dominação ocidental sobre o resto do sistema internacional. Outros elementos incluem a luta por soberania igualitária, igualdade racial, justiça econômica e liberação cultural ${ }^{6}$. Até que ponto essa difusão ou descentralização tem sido revertida é, portanto, não só central para o entendimento do papel dos Estados Unidos, como também para compreender a natureza e desenvolvimento do sistema internacional de forma mais geral.

O primeiro fator relaciona-se à utilidade da força militar e aos argumentos correntes sobre a sua utilidade declinante. Esse era um tema comum dos anos 70 , tanto na literatura mais geral sobre poder e interdependência, como nos textos mais específicos sobre força militar e sobre o porquê das grandes nações crescentemente perderem pequenas guerras. Não é necessário deter-se nos elementos específicos desse debate. Basta dizer que, com a leitura dessa posição, é possível traçar, claramente, um caminho da certeira dominação, com a qual

\footnotetext{
${ }^{5}$ De qualquer modo que expliquemos o balanço entre esse dois, o sentido de se ter uma missão de revisar o mundo talvez explique o que freqüentemente parece intrigante para os de fora - o sentido subjetivo de vulnerabilidade quando, para um analista de fora, é a ausência de ameaças e ameaçadores que é o que mais impressiona. Williams coloca isso da seguinte forma: “...a fé na singularidade dos Estados Unidos, juntamente com o fracasso de outros em copiar a perfeita revolução, gerou um sentimento profundo de estar 'sozinho'". Americanos consideravam-se perpetuamente sitiados e citavam a nota de Weinberg sobre "um sentimento de um direito natural de segurança". WILLIAMS, 1980: 53-54.

${ }^{6}$ BULL e WATSON, 1980. Na década de 70 , muito do que se escrevia relevava a questão da difusão e descentralização do poder, que eram vistas como complicando não só impérios formais como concepções hierárquicas de ordem e noçôes Kissingeristas de sistemas dominados por superpotências ou por um ordenamento oligárquico das Grandes Potências.
} 
os poderes imperiais coletivamente suprimiram a rebelião dos Boxers em 1900, às falhas militares dos impérios europeus na Argélia, sul da África, ou Indochina, assim como a derrota dos Estados Unidos no Vietnã em 1975, e as dificuldades encontradas pela União Soviética no Afeganistão de sua invasão em 1979, a sua retirada em $1989^{7}$.

O poder militar talvez seja a área mais óbvia onde os proponentes da reasserção hegemônica podem indicar uma mudança significativa e de grande extensão. Tais argumentos geralmente enfatizam a transformação de tecnologias militares, a revolução em questôes militares e a assombrosa distância que surge entre os Estados Unidos e todos os outros países, em decorrência das diferenças de novas tecnologias, dos grandes gastos e da capacidade organizacional. Daí, a ênfase no impacto de uma ampla gama de tecnologias sobrepostas: o grande crescimento da capacidade de processar informação e de penetrar a "névoa da guerra" "; o crescente raio de ação, precisão e letalidade dos sistemas bélicos; a emergência de um novo padrão de guerra com forças móveis, flexíveis e articuladas em rede (para uma clara introdução ver Freedman, 1998). Disso decorre, também, o argumento que, além de permitir ganhar guerras mais facilmente, esses desenvolvimentos também serviriam para reduzir o fardo e o perigo do uso da força militar: devido à redução de baixas, por permitir maior discernimento, por facilitar a obtenção de apoio doméstico para a guerra, por tornar mais fácil a obediência ao direito internacional humanitário, e por diluir a urgência de o país manter alianças e bases militares no estrangeiro.

À luz desses desenvolvimentos, alguns têm tentado revisar, se não reverter, a histórica trajetória notada acima. Dessa forma, Niall Ferguson compara o atual poder militar dos Estados Unidos à vitória britânica em Omdurman em 1898, quando 45.000 dos 52.000 soldados do exército de Mahdi foram mortos com somente 48 baixas do lado britânico (Ferguson, 2003). Logo, também, a tendência de lembrar as palavras de Hilaire Belloc: Whatever, happens we have got/the Maxim-gun; and they have not ("Aconteça o que for, nós temos a arma máxima; e eles não"). Para muitos, a experiência dos Estados Unidos na década de 1990, representou o restabelecimento da utilidade da força de coerção militar a custos relativos muito baixos: não somente a Guerra do Golfo (1991) envolveu menos baixas que as esperadas, como as perdas no Haiti, Somália, Bósnia e Kosovo totalizaram menos que cinqüenta mortes.

Mas, embora esse quadro sugira uma mudança fundamental, a realidade é bem mais complexa. A primeira resposta é bastante conhecida: se os opositores no campo de batalha forem racionais, vão escolher evitar lutar em termos que

\footnotetext{
7 Para se ter uma fonte relevante que focaliza as dificuldades crescentes do uso da força militar veja BLACK, 1998: especialmente os capítulos 7 e 9. Para as tendências como vistas na década de 70 veja MACK, 1975 e KNORR, 1975.

${ }^{8}$ Nota dos tradutores: expressão utilizada em inglês para indicar a enorme dificuldade que indivíduos têm em contextos de guerra para interpretar a realidade.
} 
sejam favoráveis ao mais forte - daí a noção de resposta assimétrica e o recurso ao terrorismo, à insurgência e à procura por armas de destruição em massa. As duas outras razões para dúvida podem ser frouxamente descritas como Clausewitzianas. Para Clausewitz, o uso bem-sucedido do poder coercitivo relaciona-se ao fim da motivação do oponente por intermédio de uma complexa mistura de violência física e moral. $\mathrm{O}$ uso bem-sucedido do poder coercitivo envolve a capacidade de mudar e de controlar as mentes de outros seres humanos - fazer com que outros se rendam a sua vontade e aceitem uma visão particular da realidade. Independentemente de sua eficácia técnica e destrutiva, uma força militar incapaz de lidar direta e brutalmente com a vontade do oponente, e que relute em pagar altos custos e baixas, possivelmente não alcançará esse critério essencial de sucesso (Clausewitz, [1832-37] 1976: especialmente o segundo capítulo do primeiro livro). A assimetria de comprometimento (entre as guerras que foram escolhidas versus o compromisso extremo e autodestrutivo do homem-bomba suicida), continua, portanto, sendo um fator limitador e importante no poder militar dos Estados Unidos.

A outra dúvida Clausewitziana, ainda mais intensa, advém diretamente do argumento clássico que o objeto da estratégia não é a vitória e que o único propósito do sucesso militar é modificar os termos de uma relação política. Dessa forma, a vitória no campo de batalha deve ser vista somente como um meio para um fim político. A dificuldade de vincular objetivos militares a resultados políticos sustentáveis tem sido o aspecto mais importante nos debates sobre a utilidade da força militar. Também foi central em muitos dos debates sobre contra-insurgência nos anos 60 e na análise do porquê dos Estados Unidos terem falhado no Vietnã na década de 1970. Essa questão também aparece em casos nos quais a "militarização" do conflito pouco ou nada fez para diminuir ou compensar uma falha geral de ações políticas, cujas raízes são políticas e sociais, como é o caso da guerra contra as drogas. E ainda, é fundamental na difícil tarefa de avançar do estágio de manutenção da paz e imposição da paz para o estágio da reconstrução pós-conflito e state-building.

Isso nos leva ao segundo fator: resistência à dominação estrangeira. A crescente mobilização política e social das sociedades e povos antes subordinados foi central para o processo de descolonização. A realidade do envolvimento externo genérico ou formas mais específicas de dominação estrangeira direta, combinadas com mudanças inerentes ao desenvolvimento capitalista, à expansão da educação e à disseminação de idéias sobre liberdade política, estimularam o desenvolvimento de um nacionalismo anti-colonial. Isso não ocorreu em todos os lugares e certamente não teve mesmos alcances, mas a questão crucial é que o sucesso do desenvolvimento de um império carrega em si as sementes de sua própria destruição. $\mathrm{O}$ poder do nacionalismo anticolonialista, da idéia de autodeterminação nacional e a emergência da resistência tanto das massas como das elites à dominação estrangeira representaram mudanças profundas nas 
estruturas sociais e nas mentalidades previamente subordinadas desses povos. De muitas formas, isso representou a ascensão, por todo o mundo, de um processo generalizado e universal de mudança social e desenvolvimento.

Em alguns casos, as continuidades são patentes e trabalham para reforçar o argumento sobre as dificuldades do uso da força militar. Confrontadas a resistências nacionalistas, até os Estados que estão dispostos a arcar com pesadas baixas, encontram dificuldades no uso da força militar. A Chechênia tem uma população de somente 2.5 milhões de habitantes, mas em 1994-1995, seu movimento nacionalista derrotou o exército Russo, e Moscou ainda continua sem conseguir reaver o controle estável da região, mesmo com o desejo de arcar com pesados custos e manter a subjugação brutal da região. Outros exemplos incluem Israel nos territórios ocupados, e a situação no Sri Lanka. O nacionalismo também complica a busca por padrōes estáveis de colaboração. Como notado anteriormente, os altos custos de envolvimento direto têm consistentemente levado Estados imperiais e hegemônicos ao uso de formas substitutas de dominação. Mas o desafio aqui é grande e provavelmente está aumentando: esses substitutos precisam prover segurança local eficientemente, além de preencher objetivos de segurança mais amplos (vide o antiterrorismo); também têm que ser comprometidos com valores, dado o compromisso dos Estados Unidos e de seus aliados com a democracia e os direitos humanos e as dificuldades de evadir-se da política transnacional dos direitos humanos; e, igualmente, necessitam manter tanto a confiança de seus aliados e apoios internacionais ,como aos sentimentos e necessidades de sua população, da qual suas próprias posições, em última instância, dependem.

Também é possível indagar o porquê do nacionalismo ter diminuído em importância. Em parte, esse fenômeno pode ter a ver com o poderoso legado da visão liberal da descolonização - a independência dos povos submetidos era parte dos propósitos do império, mais do que o resultado de um processo de resistência armada e conflito. Em parte, isso pode ser relacionado com as suposiçôes liberais implícitas que marcaram tanto o renascimento do multilateralismo da década de 1990, como a mais recente militância Wilsoniana - a visão segundo a qual a obtenção de autodeterminação interna relativiza a necessidade de autodeterminação externa.

Por outro lado, a importância decrescente do nacionalismo pode estar relacionada à tendência comum de interpretar os padrōes de violência mais perigosos e ameaçadores como novos. Muitos vêem a "nova onda" de terrorismo transnacional religioso como indicação de uma ruptura decisiva na evolução do terrorismo realizado por grupos não-estatais. Há, certamente, muita novidade no que se refere às condições, meios de operação e, em alguns casos, metas e objetivos. Mas o nacionalismo e a luta por autodeterminação têm sido, por muito tempo e de forma proeminente, facetas do terrorismo e assim permanecem (Rapoport, 2004: 46-73). Isso foi evidente no caso do papel que 
o terrorismo teve na luta anticolonial e na criação de Estados como Irlanda, Israel, Quênia e Argélia. Ainda que vários movimentos radicais na década de 1970 tenham se expressado na linguagem do internacionalismo, metas nacionalistas permaneceram proeminentes, como no caso de bascos, irlandeses e palestinos. E na chamada onda religiosa que se desenvolveu no fim dos anos 70, o vínculo bem próximo entre identidade religiosa e étnica, assim como a relação entre violência terrorista e a meta de autodeterminação e resistência à dominação estrangeira. Dessa perspectiva, movimentos terroristas religiosos de natureza claramente transnacional são exceçôes. Focalizando o terrorismo suicida, a questão fica ainda mais clara: "Do Líbano e Israel até Sri Lanka, Caxemira e Chechênia, todas as campanhas suicidas de 1980 a 2001 foram realizadas por grupos terroristas que têm como principal objetivo estabelecer ou manter a autodeterminação para suas comunidades por intermédio da tentativa de compelir um inimigo à retirada" (Pape, 2002: 344).

Grande parte das teses da questão da reasserção hegemônica depende da crença que essas ameaças e inimigos são localizadas (como os Estados-pária), ou personalizadas (como com Saddam Hussein ou Slobodan Milosevic); e que ideologias de revolta ou resistência legitimadoras ou unificadoras simplesmente estão ausentes. Não há nenhuma razão para acreditar que a forma específica do anticolonialismo nacionalista do século XX, deva perdurar indefinidamente. Ao contrário, o nacionalismo anticolonial deve ser visto como uma ilustração de um fenômeno mais amplo que pode ser chamado de resistência subalterna. Essa resistência pode ter alvos difusos (como o 'ocidente' ou a 'globalização') ou indivíduos detentores de poder local, assim como forças externas; seus objetivos podem ser bem menos definidos que os dos nacionalistas anticoloniais, que buscavam a criação de um novo Estado-nação, e pode ser intimamente ligado ao processo de transnacionalização e desterritorialização ${ }^{9}$. É possível, contudo, que fontes mais profundas de convergência e integração (como globalização e propagação da democracia), e o atrativo soft power dos Estados Unidos façam a resistência subalterna ao controle direto e a modos verticalizados de governança bem menos importantes que no passado. Mas há um grande terreno para questionar tanto a atual negligência do nacionalismo nas discussóes de hegemonia, como a crença que a resistência subalterna e a luta por reconhecimento por parte dos dominados e marginalizados vão continuar a ser forças poderosas ${ }^{10}$. No mínimo, é mister reconhecer e debater explicitamente a imensa importância do argumento de que algo fundamental mudou.

\footnotetext{
9 Desterritorialização e a continuidade de resistência são dois dos temas mais importantes discutidos em ROY, 2002: especialmente 41-54, e 328-340.

$10 \mathrm{Na}$ discussão recente de Stephen Krasner sobre suspending sovereignty e estados falidos a questão do nacionalismo não é mencionado como um problema. Nos termos desse autor, avareza, desespero e eleições vão sustentar a aceitabilidade de semi-soberania. KRASNER, 2004: especialmente 113-118.
} 
O terceiro fator a ser considerado refere-se à política interna do poder metropolitano. A maior parte da historiografia do fim dos impérios concentrase nos desenvolvimentos internos da metrópole imperial: a falta de desejo de arcar com os custos do império, a mudança da guerra (warfare) para o bemestar (welfare), assim como o declínio da mentalidade imperial, uma parte tão importante do funcionamento daquelas sociedades dominantes. $\mathrm{O}$ imperialismo europeu não era caracterizado somente por formas específicas de comportamento de política externa, mas fundava-se na existência de sociedades e ideologias extremamente imperialistas, tanto no plano da opinião pública como no da mentalidade oficial. O debate é colocado comumente em termos da força de vontade imperial: diz o argumento, que os impérios europeus entraram em colapso quando os europeus perderam a vontade de dominar e o desejo de arcar com os custos do império.

Como isso se encaixa no caso dos Estados Unidos? De muitas formas, a posição dos Estados Unidos parece relativamente favorável. Tanto Kojève como Negri Hardt estão errados ao sugerir que formações imperiais modernas não têm um núcleo nacional (Hardt and Negri, 2000). Os Estados Unidos são, afinal, um Estado-nação imperial com uma capacidade impressionante de mobilização nacionalista e têm um Estado que tem sido, há muito tempo, bem mais 'forte' do que a mitologia sugere. Realmente, é a combinação desses traços com as características não-territoriais e transnacionais de sua projeção de poder que está na base de seu sucesso e sustentabilidade. Embora haja muitas tensões e fissuras (especialmente durante seus maiores períodos de expansão, imigração e desenvolvimento econômico), e apesar das dúvidas recorrentes dos conservadores (Kennan anteriormente, Huntington mais recentemente), por qualquer critério de comparação, os Estados Unidos têm sido, e permanecem, um Estado-nação socialmente efetivo e coeso (Huntington, 2004).

Os pré-requisitos domésticos da hegemonia são complexos e é difícil articulá-los em uma análise geral. A visão pós-Vietnã de que a política externa dos Estados Unidos, e especialmente o uso da força, tende a ser severamente constrangida pela opinião pública, está dando lugar à visão que vê a opinião pública como muito sensível a baixas, mas não completamente avessa a elas, estando disposta a apoiar, pragmaticamente, projetos externos factíveis e compatíveis com valores norte-americanos. Mas o desejo em arcar com os custos do império em termos de sangue e recursos não é a única forma, nem necessariamente a mais importante, pela qual os fatores domésticos ganham relevância - como nos debates convencionais sobre como suplantar "os fantasmas do Vietnã". Se, como sugerido acima, a hegemonia refere-se à coerção e ao consenso, além da capacidade de recompensar aliados e realizar arranjos com colaboradores, então esse conjunto complexo e mutável de barganhas externas deve ser internalizado na política doméstica dos Estados Unidos. Dessa forma, 
os reais constrangimentos domésticos são muito menos relacionados com a questão dos custos do que com a grande dificuldade de compatibilizar a dimensão externa do gerenciamento hegemônico, com o caráter extremamente complexo, fechado e introspectivo da política doméstica americana.

Em quarto lugar está o papel desempenhado por mudanças no ambiente legal e normativo. Desse ponto de vista, o progressivo desenvolvimento da luta contra o império refletiu-se em numerosas mudanças cruciais nas normas dominantes da sociedade internacional e foi reforçada por elas: o aumento das limitações ao uso da força, especialmente em relação à conquista, controle forçado e ocupação; e a crescente centralidade da norma de autodeterminação. De várias formas, mudanças legais e normativas na década de 1990, pareceram estar andando na direção oposta. Exemplos disso incluem a crescente aceitação da necessidade de repensar e reconceitualizar soberania; a crescente concordância com o argumento segundo o qual os novos desafios da segurança necessariamente acarretam o envolvimento profundo nos assuntos de outros Estados, especialmente os mais fracos; o estabelecimento de administraçóes internacionais para administrar territórios, cuja soberania foi suspensa; o retorno mais amplo em direção a idéias sobre protetorados e noções graduais de soberania, muito familiares aos textos jurídicos do final do século XX; e a propagação de idéias sobre intervenção humanitária, segurança humana e a responsabilidade de proteção.

No entanto, devem-se notar quatro questóes. Primeiramente, embora possa ser correta a afirmação de que o caráter da ordem legal reflete padrōes do poder hegemônico e o interesse das grandes potências, também é correto afirmar que controlar uma ordem legal cada vez mais complexa e pluralista é bem mais difícil hoje que há cem anos, quando o direito internacional era feito pelas grandes potências imperiais e para elas. Essa é uma razão estrutural para explicar o crescimento da frustração dos Estados Unidos com o direito internacional. Em segundo lugar, as mais importantes limitações normativas ainda estão presentes, especialmente em termos de normas contra a conquista e a favor da autodeterminação. Ainda, outros desenvolvimentos normativos, principalmente no campo dos direitos humanos, têm complicado em grande medida o uso da coerção. Certamente é verdade que a guerra ao terror representou uma profunda mudança na questão dos direitos humanos em várias partes do mundo, mas é também certo que a reação a esses desafios demonstra pelo menos um certo grau de assentamento da cultura dos direitos humanos, que se tornou uma parte central da visão liberal solidarista da sociedade internacional.

Em terceiro lugar, para tirar vantagens dos potenciais benefícios da ordem legal, os Estados Unidos têm que se engajar nela. De fato, visto de fora, a característica mais marcante do período pós-11 de Setembro foi a falha daquele país em engajar-se de forma mais sistemática com a ONU e o direito internacional, em uma época em que vários aspectos da ordem legal estavam caminhando a seu favor. Mas, em quarto lugar, e em direção oposta, os Estados Unidos escolheram 
dois conjuntos de normas para os quais o consenso na sociedade internacional é muito difícil de se conseguir - certamente se for fora de um comprometimento mais profundo com processos e procedimentos. O primeiro conjunto tem a ver com o uso da força e a enunciação de uma doutrina expandida de preempção e prevenção, que representa claramente uma mudança profunda nos atuais entendimentos legais sobre a justificativa do uso da força. O segundo conjunto é o da noção emergente de soberania qualificada ou condicional, que precisa de definições mais nítidas: por exemplo, por meio da argumentação de que alguns tipos de Estados perderam o direito soberano de possuir certos tipos de armamentos, ou de que em casos de soberania condicional ou qualificada é legítimo intervir para mudar o regime político interno.

Finalmente, há a questão sobre os oponentes e potenciais desafiadores. Como foi sugerido anteriormente, esse não é o único fator que precisa ser considerado, mas seu exame é inevitável. O fim dos impérios europeus esteve ligado intimamente à existência de um equilíbrio de poder global e à dinâmica de competição entre as superpotências, dinâmica essa que gerou oportunidades para os Estados mais fracos e os movimentos nacionalistas. Igualmente, quaisquer seja o papel atribuído à pressão externa, o fim do império soviético só pode ser entendido dentro do contexto da Guerra Fria e da rivalidade bipolar. Sem pretender apresentar um quadro completo, duas posições podem ser identificadas.

A primeira posição é alta, mas não exclusivamente, baseada na noção de poder. Essa explicação assenta-se em três proposições. Em primeiro lugar, que a dominação dos Estados Unidos é estável devido à absoluta extensão do poder americano e à impossibilidade de existir qualquer desafio ou desafiante a esse poder. Em segundo lugar, que é possível negociar suficiente apoio para as posiçóes dos Estados Unidos. Em alguns casos, o apoio vem da dependência na área da segurança (dadas as falhas dos mecanismos de segurança coletivos), da importância do poder dos Estados Unidos nos equilíbrios de poder regionais, e do argumento que somente os Estados Unidos podem lidar com desafios comuns, como o terrorismo e as armas de destruição em massa. Em outros casos, o apoio deriva do poder econômico norte-americano, tanto em termos de incentivos como de constrangimentos. E, em terceiro lugar, o poder dos Estados Unidos é estável porque ele realmente tem por base propósitos legítimos. É interessante notar que, até mesmo entre os neoconservadores, os argumentos sobre legitimidade têm se tornado mais proeminentes, tanto a legitimidade de resultados, referente aos bens públicos que só os Estados Unidos podem prover ao mundo, como também a legitimidade de valores sociais compartilhados, especialmente a liberdade e a democracia (por exemplo Kagan, 2004).

No entanto, esse argumento encontra sérias dificuldades. Primeiro, ele vê a política do equilíbrio de poder unicamente em termos de desafios e desafiadores militares. O problema do poder não-equilibrado não é que ele vá, inevitavelmente, pôr seus tanques em operação. $\mathrm{O}$ que ocorre é que o poder 
radicalmente não-equilibrado vai permitir que o mais poderoso imponha leis aos menos poderosos, distorcendo os termos de cooperação a seu favor, impondo seus próprios valores e modus operandi, e minando os procedimentos dos quais depende a cooperação estável e sustentável. É por essa razão que a notada necessidade de "conter" os Estados Unidos atualmente é a resposta racional pluralista, não precisando ser relacionada a qualquer anti-americanismo político ou cultural e, menos ainda, à noção de que os Estados Unidos representam uma "ameaça" num sentido militar ultrapassado. Ainda que persista apenas como pano-de-fundo, o equilíbrio de poder continua a ter relevância e, em relação a isso, não é coincidência que dois dos mais elaborados exemplos de sucesso na construção de instituições, a União Européia e a Organização Mundial de Comércio, reflitam relações de poder relativamente equilibradas.

O segundo problema com esse argumento é que minimiza o desejo dos principais Estados afetados em desenvolver novas formas de equilíbrio para limitar a potência norte-americana. Enquanto a possibilidade de um equilíbrio mais profundo possa estar fora de cogitação, esse não é o caso de exercícios de equilíbrio mais limitados e leves. Portanto, rivais potenciais certamente têm estado dispostos a realizar acordos com os Estados Unidos, mas eles também se dispõem a complicar e aumentar os custos das políticas norte-americanas em algumas instituiçóes internacionais (pela negação de legitimidade), e a desafiar as preferências dominantes em outras (como os países em desenvolvimento na OMC). E, terceiro, as pretensões de legitimidade não parecem ganhar adeptos em grande parte do mundo, mesmo entre aqueles que compartilham os mesmos valores políticos e culturais.

Uma forma alternativa de observar as escolhas estratégicas do hegemon é no âmbito dos esforços para constitucionalizar seu poder e ganhar a aceitação de sua proeminência. Essa idéia é antiga. Para Aron, por exemplo, a escolha para um potencial hegemon é clara: "Ou uma grande potência não vai tolerar a igualdade, e deve então buscar o último grau de império, ou ele outorga-se a posição de primazia entre as unidades soberanas, tendo que ganhar a aceitação dessa proeminência” (Aron, 1966: 70). Nesse último caso, é crucial a idéia da auto-restrição estratégica e o papel das instituições. Se a potência dominante deseja manter sua posição predominante, então ela deve agir com essa autorestrição estratégica para prevenir a emergência de potências rivais. Dessa forma, um hegemon racional vai agir com auto-restrição e limitações de ordem institucional de forma a diminuir a percepção de ameaça por parte de outros Estados.

John Ikenberry fornece uma das mais claras explicaçôes dessa lógica. Em todos os seus trabalhos recentes, ele tem enfatizado o caráter distinto, aberto e institucionalizado da hegemonia dos Estados Unidos e da barganha "liberal" que Washington foi capaz de realizar para lidar com as "incertezas do poder americano": Estados asiáticos e europeus concordam em aceitar a liderança americana e operar dentro de um sistema político-econômico acordado. Em 
troca, os Estados Unidos abrem-se e atam-se aos seus parceiros, construindo uma coalizão institucionalizada de parceiros e reforçando a estabilidade dessas relações de longo prazo, tornando-se mais 'user friendly' - isto é, jogando de acordo com as regras estabelecidas e criando processos políticos contínuos com esses Estados que facilitam a consulta e a tomada de decisóes conjunta (Ikenberry, 2001a: 27; e Ikenberry, 2001b).

Ainda é cedo para julgar se os Estados Unidos vão ser capazes de restabilizar a sua hegemonia por essa rota; mas existem três questōes que serão cruciais. A primeira relaciona-se com o grau em que o engajamento institucional norteamericano é genuíno. É suficiente, como Richard Betts tem argumentado, para Washington ir "por intermédio de moções de consulta, apoiando retoricamente as instituições internacionais mesmo que ele as menospreze em última instância"? (Betts, 2005: 13). Afinal de contas, fora do Atlântico Norte, até que ponto Washington tem desejado algo minimamente semelhante a um genuíno esforço de consulta ou "processo decisório conjunto"? A segunda é o grau pelo qual o enredamento institucional com o Estado dominante pode enfraquecer, ao invés de fortalecer, outros Estados. Sim, existem grandes incentivos que pressionam Estados fracos em direção às instituições, mas também há um ponto no qual os valores e os interesses representados pelas instituições são extremamente favoráveis aos mais poderosos, ou no qual os procedimentos para mitigar a desigualdade de poder não podem ser utilizados de forma efetiva pelos mais fracos (ou podem facilmente ser contornados pelos mais fortes). A terceira questão relaciona-se com o balanço de satisfação e com a forma pela qual esse balanço é, ou não, visto como legítimo por um conjunto consideravelmente amplo da opinião política. A definição clássica de grande potência, afinal, é aquele Estado que está disposto a ter uma concepção ampla de seus próprios interesses e tem por objetivo criar um sistema no qual a maioria dos Estados e indivíduos se vêem como tendo algum grau de participação.

\section{Conclusões}

As fontes de poder dos Estados Unidos são de fato enormes. Mas o que é mais notável é a instabilidade desse poder, suas incertezas e a dificuldade perene de se traduzir poder em resultados desejados, especialmente duráveis em um mundo cada vez mais complexo. Na medida em que os Estados Unidos buscam uma concepção rígida e exclusivista de seus próprios interesses e propõem uma concepção estreita e hegemônica de ordem, então é possível gerar não uma Pax Americana, mas sim um império da insegurança, tanto para si mesmos como para outros. Os desafios às estruturas da sociedade internacional provavelmente se tornarão mais sérios e as dificuldades de reparos institucionais ficarão mais difíceis. Mas, mesmo se entrarmos em um período de descompressão hegemônica, então precisaremos nos perguntar o quanto os fatores examinados nesse trabalho também complicam a busca por alternativas. 
Afinal, é uma ilusão dos críticos da administração Bush que possa haver uma alternativa multilateral simples, pronta e esperando para ser implantada. Nesse sentido, a legitimidade do multilateralismo liberal da década de 1990, já foi questionada por muitos Estados (e movimentos sociais), com o desenrolar da década. Para esses, a retórica do multilateralismo liberal encobre seu real caráter hierárquico, prescritivo e frequentemente coercitivo. Os resultados substantivos pareceram estar em favor do mais poderoso: segurança coletiva havia tornadose segurança seletiva; a agenda de direitos humanos beneficiava a democracia, e direitos civis e políticos, mas negligenciava direitos econômicos e sociais, e ignorava pedidos por maior justiça econômica; e, apesar de a globalização econômica ser altamente promovida, pouca atenção era dada às suas insatisfações e desvantagens. A linha-dura hegemônica do "nós podemos fazer isso sozinhos" está claramente equivocada. Mas a versão hegemônica liberal, "nós podemos fazer isso juntos" depende de quem 'nós' somos, do que 'isso' significa, e do que se quer dizer com 'juntos'.

Recebido em 28 de junho de 2005 Aprovado em 15 de setembro de 12005

\section{Referências bibliográficas}

ARON, Raymond. Peace and War. A Theory of International Relations. London: Weidenfeld and Nicolson, 1966.

BACEVICH, Andrew J. American Empire. The Realities and Consequences of U.S. Diplomacy. Cambridge, MA: Harvard University Press, 2002.

BETTS, Richard. The Political Support System for American Primacy. In: International Affairs 81, n.1, 2005. p 1-14.

BLACK, Jeremy. War and the World. Military Power and the Fate of Continents. New Haven: Yale University Press, 1998.

BROOKS, Stephen G. \& WOHLFORTH, William C. American Primacy in Perspective. In: Foreign Affairs 81, n. 4, 2002. p. 20-34.

BULL, Hedley \& WATSON, Adam (eds.). The Expansion of International Society. Oxford: Oxford University Press, 1980.

CLAUSEWITZ, Carl von. On War, Edited and Translated by Michael Howard and Peter Paret. Princeton: Princeton University Press, 1832/37.

CARR, E.H. Nationalism and After. London: Macmillan, 1945.

Cobden, Richard. The Political Writings of Richard Cobden. London: T. Fisher Unwin, 1867/1903. COWLEY, E.H. The American Diaries of Richard Cobden. Princeton: Princeton University Press, 1952.

COX, Michael. The Empire's Back in Town: Or America’s Imperial Temptation - Again. In: Millennium. vol. 32, n. 1. 2003.

DARWIN, John. Imperialism and the Victorians. The Dynamics of Territorial Expansion. In: English Historical Review CXII, 447, 1997. p.614-642 
FERGUSON, Niall (2003) Empire: The Rise and Demise of the British World Order and the Lessons for Global Power. New York, Basic Books.

FREEDMAN, Lawrence. The Revolution in Strategic Affairs Adelphi Paper 318. London: IISS, 1998.

GALLAGHER, John \& ROBINSON, Ronald. The Imperialism of Free Trade', Economic History Review VI, n. 1, 1953 p. 1-15.

GILDERHUS, Mark T. Pan-American Initiatives: The Wilson Presidency and "Regional Integration", 1914-1917. In: Diplomatic History 4, n. 4, 1954. p. 409-423.

GILDERHUS, Mark T. Pan-American Visions: Woodrow Wilson and the Western Hemisphere, 1913-1921. Tucson: University of Arizona Press, 1986.

HARDT, Michael \& NEGRI, Antonio. Empire. Cambridge: Harvard University Press, 2000.

HOFFMANN, Stanley. Why Don't they Like Us?. In: WITTKOPF, Eugene R \& MACCORMICK, James M. (eds.). The Domestic Sources of American Foreign Policy. Insights and Evidence. Lanham: Rowman and Littlefield. 2004.

HUNTINGTON, Samuel. Political Order in Changing Societies. New Haven: Yale University Press, 1968.

HUNTINGTON, Samuel. Who Are We? Americas Great Debate. New York, Free Press, 2004.

IKENBERRY, G. John. American Grand Strategy in the Age of Terror. In: Survival. vol. 43, n. 4, 2001 p.19-34.

IKENBERRY, G. John.After Victory: Institutions, Strategic Restraint, and the Rebuilding of Order after Major War. Princeton: Princeton University Press, 2001.

IKENBERRY, G. John. America's Imperial Ambition. In: Foreign Affairs vol. 81, n. 5, 2002. p. 44-62.

KAGAN, Robert. America’s Crisis of Legitimacy. In: Foreign Affairs. vol. 83, 2, 2004. p. 65-88. KNORR, Klaus. Is International Coercion Waning or Rising?. In: International Security. vol.1, n. 4, 1975. p. 92-110.

KOJÈVE, Alexandre. (August 27, 1945) Outline of a Doctrine of French Policy. Translated by Erik de Vries and with commentary by Robert Howse. Reprinted in Policy Review. Disponível em: <http://www.policyreview.org/aug04>, accessed in 05/11/2004.

KRAMER, Paul A. Empires, Exceptions, and Anglo-Saxons: Race and Rule between the British and United States Empires, 1880-1910. In: The Journal of American History vol. 88, n. 4, 2002.

KRASNER, Stephen D. (Fall 2004) 'Sharing Sovereignty: New Institutions for Collapsed and Failing States. In: International Security. vol.29, n. 2, fall 2004. p. 85-120.

LISKA, George. Imperial America: The International Politics of Primacy. Baltimore: Johns Hopkins University Press, 1967.

MACK, Andrew. Why Big Nations Lose Small Wars. The Politics of Asymmetric Conflict. In: World Politics. vol.27, n.2, 1975. p. 175-200.

MAY, Ernest R. American Imperialism: A Speculative Essay. New York: Atheneum, 1968.

MORGENTHAU, Hans J. The Purpose of American Politics. New York: Alfred A. Knopf, 1960.

MÜLLER, Jan-Werner. A Dangerous Mind: Carl Schmitt in post-war European Thought. New Haven: Yale University Press, 2003.

PAKENHAM, Robert. Liberal America and the Third World. Princeton: Princeton University Press, 1973. 
PAPE, Robert A. The Strategic Logic of Suicide Terrorism', American Political Science Review. vol.97, n.3, 2002. p. 343-361.

RAPOPORT, David C. The Four Waves of Modern Terrorism. In: CRONIN, Audrey Kurth \& LUDES, James M. (eds.). Attacking Terrorism. Elements of Grand Strategy. Washington DC: Georgetown University Press, 2004. p. 46-73.

ROY, Olivier. Globalized Islam. The Search for a New Ummah. London: Hurst and Company, 2002.

SCHOULTZ, Lars. Beneath the United States: A History of U.S. Policy toward Latin America. Cambridge, MA: Harvard University Press, 1999.

SEELEY, J.R. The Expansion of England. Edited and introduced by John Gross. Chicago: University of Chicago Press, 1881/1971.

SNYDER, Jack. Myths of Empire. Domestic Politics and International Ambition. Ithaca: Cornell University Press, 1991.

SNYDER, Jack. Imperial Temptations. In: The National Interest. n. 71, 2003. p. 29-41.

TRIEPEL, Heinrich. Die Hegemonie: Ein Buch von Führenden Staaten. Stuttgart. 1938.

WILLIAMS, William A. Empire As a Way of Life. Oxford: Oxford University Press, 1980.

ZAKARIA, Fareed. From Wealth to Power. The Unusual Origins of America's World Role. Princeton: Princeton University Press, 1998.

ZIMMERN, Alfred. The Third British Empire. 3 ed., Westport: Greenwood, 1934/1979.

\section{Resumo}

No artigo pretende-se mostrar a posição dos Estados Unidos em um diferente contexto conceitual e histórico, como tentativa de escapar-se do imediatismo da discussão atual do país como um poder imperial ou hegemônico, trazidos pelos debates atuais. Revelase assim, problemas de definições dos conceitos de imperialismo e hegemonia, assim como da dominação formal/infomal distorcendo a real imagem e posição da América do Norte no campo internacional nos dias atuais.

\section{Abstract}

The article intends to show the position of the United States in a different conceptual and historical context, as attempt to run away itself of the immediacy of the current debate of the state as one to be able imperial or hegemonic, brought for the current discussion. It discloses thus, problems of definitions of the concepts of imperialism and hegemony, as well as of the formal and informal domination, distorting the real image and position of North America in the international field in the current days.

Palavras-chave: Estados Unidos - Imperialismo - Multilateralismo/Unilateralismo Key words: United States - Imperialism - Multilateralism/Unilateralism 